Article

\title{
In situ synthesis of a nickel boron oxide/graphdiyne hybrid for enhanced photo/electrocatalytic $\mathrm{H}_{2}$ evolution
}

\author{
Xue-Peng Yin †, Shu-Wen Luo ${ }^{\dagger}$, Shang-Feng Tang, Xiu-Li Lu*, Tong-Bu Lu \# \\ MOE International Joint Laboratory of Materials Microstructure, Institute for New Energy Materials and Low Carbon Technologies, School of Material \\ Science \& Engineering, Tianjin University of Technology, Tianjin 300384, China
}

\section{A R T I C L E I N F O}

Article history:

Received 6 January 2020

Accepted 2 February 2020

Available online 5 April 2021

Keywords:

Graphdiyne

Hybrid material

Photo/electrocatalyst

Water splitting reaction

$\mathrm{H}_{2}$ evolution

\section{Introduction}

Energy shortages and environmental issues have triggered considerable interest in alternative energy storage and conversion systems [1]. Hydrogen is regarded as a potential substitute for traditional fossil fuels, due to its high energy density and green combustion products [2,3]. Photo/electrocatalytic water splitting is a promising way of converting solar and electric energy into chemical fuels [4-7]. During the past few decades, significant efforts have been made to develop highly efficient catalysts for the $\mathrm{H}_{2}$ evolution reaction (HER). Until now, the best HER catalysts have been based on the noble metals, such as platinum [8]. However, the scarcity and high cost of noble metals hamper their large-scale application. Thus, it is extremely attractive to exploit earth-abundant and cost-efficient catalysts for the HER [9]. Considerable efforts have been devoted to developing new, more efficient non-noble-metal-based catalysts, such as transition-metal dichalcogenides [10-12], phosphides [13-16], carbides [17], and borates [18-20]. However, catalysts using non-noble metals alone often suffer from low active surface areas and inefficient diffusion of charge carriers, resulting in unsatisfactory catalytic performances. To improve their catalytic activities, a large number of non-noble-metal-based nanocomposites have been fabricated by integrating them on supports with high electron transfer rates and high surface areas, such as graphene $[19,21,22]$ and

\footnotetext{
* Corresponding author. Tel/Fax: +86-22-60215704; E-mail: luxiuli@email.tjut.edu.cn

\# Corresponding author. E-mail: lutongbu@tjut.edu.cn

† These authors contributed equally to this work.

This work was supported by the Science and Technology Development Fund of Tianjin Education Commission for Higher Education (2018KJ129).

DOI: 10.1016/S1872-2067(20)63601-4 | http://www.sciencedirect.com/journal/chinese-journal-of-catalysis | Chin. J. Catal., Vol. 42, No. 8, August 2021
} 
carbon nanotubes $[23,24]$. Thus, designing non-noble-metal nanocomposite materials as photo/electrocatalysts with high numbers of surface-active sites and superior stabilities is highly desirable.

Graphdiyne (GDY), a new carbon allotrope, has shown great potential for photo/electrocatalytic water splitting due to its unique chemical and electronic structure [25]. Compared to graphene and other traditional carbon materials, GDY is composed of an $s p^{2-}$ and $s p$-hybridized carbon network, which affords GDY favorable semiconductor property, superior electrical conductivity, and robust stability. GDY also possesses uniformly dispersed pores and a large specific surface area, providing an enormous number of sites for anchoring metal ions and constructing stable non-noble-metal-based nanocomposites. Therefore, GDY has been proven to be an ideal support for in situ growth of stable nanocatalysts for water splitting. To date, $\mathrm{TiO}_{2} / \mathrm{GDY}$ [26], CdS/GDY [27], and g- $\mathrm{C}_{3} \mathrm{~N}_{4} / \mathrm{GDY}$ [28] hybrids have been fabricated and applied to photocatalytic water splitting, with GDY displaying improved separation and migration of photoinduced charge carriers, leading to enhanced photocatalytic activities. In addition, $\mathrm{MoS}_{2}$ /GDY [29], WS 2 /GDY [30], CoNC/GDY [31], FeCH@GDY [32], Ni-Co-P/GDY [33], and CoLDH@GDY [34] hybrids have also been constructed to enhance their electrocatalytic water splitting performances. However, GDY has never been used to construct a nanocomposite that could be applied as a catalyst in both photocatalytic and electrocatalytic water splitting reactions for $\mathrm{H}_{2}$ evolution.

In this study, we prepared for the first time a strongly coupled nickel boron oxide/graphdiyne ( $\left.\mathrm{NiB}_{i} / \mathrm{GDY}\right)$ hybrid through a facile room-temperature chemical route, for use as a highly active HER catalyst for photo/electrocatalytic $\mathrm{H}_{2}$ evolution. $\mathrm{NiB}_{i} / \mathrm{GDY}$ displayed improved $\mathrm{H}_{2}$ evolution under visible light irradiation in aqueous solutions when using Eosin Y (EY) as a photosensitizer and triethanolamine (TEOA) as a sacrificial reagent, realizing 2.9 and 4.5 times higher $\mathrm{H}_{2}$ evolution rates than those of $\mathrm{NiB}_{i} /$ graphene and $\mathrm{NiB}_{i}$, respectively. Furthermore, $\mathrm{NiB}_{i} / \mathrm{GDY}$ showed high HER electrocatalytic activity, achieving a current density of $400 \mathrm{~mA} / \mathrm{cm}^{2}$ at an overpotential of $478.0 \mathrm{mV}$, lower than that of commercial Pt/C (505.3 $\mathrm{mV} @ 400 \mathrm{~mA} / \mathrm{cm}^{2}$ ). The improved catalytic performance can be attributed to the formation of strongly coupled $\mathrm{NiB}_{i} / \mathrm{GDY}$, in which the strongly electron donating GDY optimized the electronic structure of $\mathrm{NiB}_{i}$ with lower valence Ni sites. These results demonstrate that GDY could be a promising support for in situ synthesis of nanocomposites as highly active photo/electrocatalysts.

\section{Experimental}

\subsection{Catalyst preparation}

\subsubsection{Synthesis of graphdiyne}

GDY was synthesized via an acetylenic cross-coupling reaction, as previously reported [25,35].

For the synthesis of GDY powder, $33 \mathrm{mg}$ of hexaethynylbenzene (HEB) was dissolved in pyridine and slowly added to a three-necked flask containing copper foils immersed in pyridine. The mixture was protected from light and then heated for $72 \mathrm{~h}$ at $110{ }^{\circ} \mathrm{C}$ under an Ar atmosphere. After completion of the reaction, the GDY was washed with hot DMF, acetone, $\mathrm{HCl}, \mathrm{NaOH}$, and water in turn, and then dried at $50{ }^{\circ} \mathrm{C}$ under vacuum for $12 \mathrm{~h}$.

For the synthesis of GDY nanowalls, HEB $(10 \mathrm{mg})$ was dissolved in acetone and added slowly to a three-necked flask containing five treated $\mathrm{Cu}$ foams immersed in a mixture of acetone, pyridine, and tetramethylethylenediamine (TMEDA) with a volume ratio of 100:5:1. The mixed solution was heated in the dark and under an Ar atmosphere for $12 \mathrm{~h}$ at $50{ }^{\circ} \mathrm{C}$. After the reaction, the GDY nanowalls grown on the $\mathrm{Cu}$ foams were washed sequentially with heated DMF and acetone, and dried at $50{ }^{\circ} \mathrm{C}$ under vacuum for $12 \mathrm{~h}$.

\subsubsection{Synthesis of $N i B_{i} / G D Y$}

For $\mathrm{NiB}_{i} /$ GDY used in photocatalytic HER, GDY powder (8 $\mathrm{mg}$ ) was dispersed into $4 \mathrm{~mL}$ of ultrapure water. Then, an aqueous solution of $\mathrm{Ni}\left(\mathrm{NO}_{3}\right)_{2}(40 \mathrm{mM}, 508 \mu \mathrm{L})$ was added to the GDY solution with continuous stirring. After $3 \mathrm{~min}, 100 \mu \mathrm{L}$ of a sodium borohydride $\left(\mathrm{NaBH}_{4}\right)$ solution $(3 \mathrm{mg} / \mathrm{mL})$ was added for a further 2 min. The obtained $\mathrm{NiB}_{i} /$ GDY was then washed and dried overnight under vacuum.

For $\mathrm{NiB}_{i} / \mathrm{GDY}$ used in electrocatalytic HER, a piece of GDY nanowall was immersed in a solution of $\mathrm{Ni}\left(\mathrm{NO}_{3}\right)_{2}(40 \mathrm{mM}, 20$ $\mathrm{mL}$ ) for $40 \mathrm{~min}$. Then, an $\mathrm{NaBH}_{4}$ solution $(0.5 \mathrm{M}, 4 \mathrm{~mL})$ was added and allowed to react for another $2 \mathrm{~h}$. After the reaction, the $\mathrm{NiB}_{i} / \mathrm{GDY}$ was washed with pure water to get rid of extra $\mathrm{Ni}^{2+}$ and $\mathrm{NiB}_{i}$. The $\mathrm{NiB}_{i} /$ GDY sample was obtained after drying in air.

\subsubsection{Synthesis of $\mathrm{NiBi} /$ graphene}

Graphene (8 $\mathrm{mg}$ ) was homodispersed in $4 \mathrm{~mL}$ of ultrapure water. Subsequently, an aqueous solution of $\mathrm{Ni}\left(\mathrm{NO}_{3}\right)_{2}(40 \mathrm{mM}$, $508 \mu \mathrm{L}$ ) was added to the graphene solution under continuous stirring. After reacting for $3 \mathrm{~min}, 100 \mu \mathrm{L}$ of $\mathrm{NaBH}_{4}$ solution (3 $\mathrm{mg} / \mathrm{mL}$ ) was added for another $2 \mathrm{~min}$. The $\mathrm{NiB}_{i} /$ graphene was obtained after washing and drying under vacuum overnight.

\subsubsection{Synthesis of $\mathrm{NiB}_{i}$}

$\mathrm{NaBH}_{4}$ solution $(0.5 \mathrm{M}, 4 \mathrm{~mL})$ was added to an aqueous solution of $\mathrm{Ni}\left(\mathrm{NO}_{3}\right)_{2}(40 \mathrm{mM}, 20 \mathrm{~mL})$ under continuous stirring. After reacting for $2 \mathrm{~h}$ at room temperature, a black sample was acquired by centrifugation and washed three times each with pure water and ethanol. The $\mathrm{NiB}_{i}$ sample was finally obtained after drying under vacuum overnight.

\subsection{Characterization}

The surface morphologies of the as-prepared samples were determined by scanning electron microscopy (SEM, Verios 460L Ultrahigh Resolution Scanning Electron Microscope) and energy dispersive X-ray spectrometry (EDS). Transmission electron microscopy (TEM) was performed using a Tecnai G2 Spirit TWIN at an acceleration voltage of $120 \mathrm{kV}$. The compositions and surface electronic states of the as-prepared samples 
were measured using X-ray photoelectron spectroscopy (XPS, ESCA LAB250Xi). Raman spectra were analyzed using a high-resolution laser confocal fiber Raman spectrometer (HORIBA EVOLVTION, HORIBA Jobinyvon, France) with an excitation wavelength of $532 \mathrm{~nm}$. A fluorescence spectrophotometer (F-7000, Hitachi, Tokyo, Japan) was employed to obtain the photoluminescence (PL) spectra. Fluorescence decay spectra were measured on a MiroTime 200 time-resolved confocal fluorescence instrument.

\subsection{Photocatalytic $\mathrm{H}_{2}$ evolution measurements}

In a typical experiment, $2 \mathrm{mg}$ of the as-prepared catalyst was dispersed in $5 \mathrm{~mL}$ of a $10 \%(\mathrm{v} / \mathrm{v})$ aqueous solution of TEOA, then $3 \mathrm{mg}$ of EY was added. Before irradiation, the solution was purged with Ar for 30 min to remove air, followed by irradiation with a $300 \mathrm{~W}$ Xe lamp equipped with a UV-cutoff filter $(\lambda>400 \mathrm{~nm})$. The reactant solution was maintained at 25 ${ }^{\circ} \mathrm{C}$ by a flow of cooling water. The evolved $\mathrm{H}_{2}$ was detected using a gas chromatograph (GC-2014+ATF, 230C, Shimadzu, Japan) equipped with a thermal conductivity detector (TCD).

\subsection{Electrochemical measurements}

Electrochemical measurements were performed on a standardized three-electrode system (CHI 760E, CH Instruments) with a working electrode, a saturated $\mathrm{Ag} / \mathrm{AgCl}$ reference electrode, and a carbon rod counter electrode. The as-prepared samples were directly used as the working electrode. Linear sweep voltammetry (LSV) measurements were performed in $1.0 \mathrm{M} \mathrm{KOH}$ electrolyte at a scan rate of $5.0 \mathrm{mV} / \mathrm{s}$. All potentials were referenced to the reversible hydrogen electrode (RHE) from the $\mathrm{Ag} / \mathrm{AgCl}$ reference electrode as follows: $E(\mathrm{RHE})=E(\mathrm{Ag} / \mathrm{AgCl})+0.198+0.059 \times \mathrm{pH}$. For comparison, 9.0 $\mathrm{mg}$ of Pt/C was dispersed in $2.5 \mathrm{~mL}$ water/ethanol $(v / v=4: 1)$ containing $100 \mu \mathrm{L}$ of a $5 \mathrm{wt} \%$ Nafion solution. The mixture was sonicated for $1 \mathrm{~h}$, then $140 \mu \mathrm{L}$ of the catalyst ink was loaded onto the $\mathrm{Cu}$ foam. The $\mathrm{NiB}_{i}$ and $\mathrm{NiB}_{i}$ /graphene inks were prepared by dispersing $4 \mathrm{mg}$ of the respective catalyst into $970 \mu \mathrm{L}$ of ethanol/water $(v: v=1: 1)$ containing $30 \mu \mathrm{L}$ of a $5 \mathrm{wt} \%$ Nafion solution and sonicating them for $1 \mathrm{~h}$. Then, $67 \mu \mathrm{L}$ of the Ni$\mathrm{B}_{i}$-containing ink or $250 \mu \mathrm{L}$ of the $\mathrm{NiB}_{i}$ /graphene-containing ink was loading onto the $\mathrm{Cu}$ foam. All tests were performed without further iR compensation.

\section{Results and discussion}

The $\mathrm{NiB}_{i} /$ GDY hybrid was prepared by a simple chemical synthesis strategy performed at room temperature. For comparison, pure $\mathrm{NiB}_{i}$ and $\mathrm{NiB}_{i}$ grown on graphene (Ni$\mathrm{B}_{i}$ /graphene) were also prepared following a similar method to prepare $\mathrm{NiB}_{i} / \mathrm{GDY}$. To prepare $\mathrm{NiB}_{i} / \mathrm{GDY}$, GDY was immersed in a solution containing $\mathrm{Ni}^{2+}$ ions, which could interact with the butadiyne linkages $(-\mathrm{C} \equiv \mathrm{C}-\mathrm{C} \equiv \mathrm{C}-)$ and anchor on to GDY, as illustrated in Scheme 1. After further reaction with $\mathrm{NaBH}_{4}$, the $\mathrm{NiB}_{i}$ nanosheets were grown in situ on the GDY, leading to the formation of the $\mathrm{NiB}_{i} / \mathrm{GDY}$ hybrid. The surface morphology and

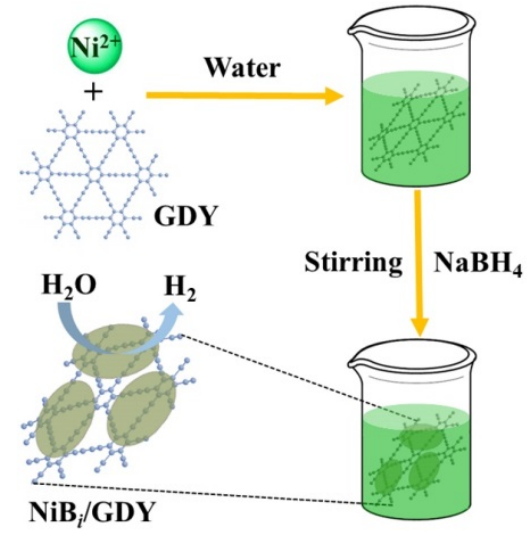

Scheme 1. The in situ growth of $\mathrm{NiB}_{i}$ on GDY at room temperature.

composition of the as-prepared $\mathrm{NiB}_{i} / \mathrm{GDY}$ were investigated by scanning electron microscopy (SEM), transmission electron microscopy (TEM), and energy dispersive X-ray spectroscopy (EDS). The SEM image of GDY (Fig. 1a) shows a nanosheet array morphology with an irregular nanowall structure. After $\mathrm{NiB}_{i}$ nanosheets were evenly grown on the surface of GDY, the surface morphology became wrinkled (Fig. 1b), indicating the successful growth of $\mathrm{NiB}_{i}$ on GDY. The TEM images further confirm the successful construction of the $\mathrm{NiB}_{i} /$ GDY hybrid (Figs. e 1c, 1d, and Fig. S1). TEM images were also obtained for Ni$\mathrm{B}_{i}$ /graphene and pure $\mathrm{NiB}_{i}$ (Fig. S2 and Fig. 1e, respectively). $\mathrm{NiB}_{i} /$ graphene showed $\mathrm{NiB}_{i}$ nanosheets homogenously organized on the surface of the graphene. Unlike $\mathrm{NiB}_{i} / \mathrm{GDY}$ and $\mathrm{Ni}-$ $\mathrm{B}_{i}$ /graphene, pure $\mathrm{NiB}_{i}$ exhibited a hierarchical structure comprised of aggregated nanosheets (Fig. 1e). In addition, the insets of Figs. 1d, 1e, and S2 show the selected area electron diffraction (SAED) patterns of $\mathrm{NiB}_{i} / \mathrm{GDY}, \mathrm{NiB}_{i}$, and $\mathrm{NiB}_{i} /$ graphene, respectively, verifying the amorphous structures of the as-prepared samples. Furthermore, the HR-TEM image (Fig. S1b) and X-ray powder diffraction (XRD) patterns (Fig. S1c) of $\mathrm{NiB}_{i} /$ GDY show no distinct lattice fringes or crystal diffraction peaks, respectively, confirming its amorphous structure [36]. EDS mapping images (Fig. 1f) also reveal uniform distributions of $\mathrm{C}$ (green), $\mathrm{Ni}$ (red), B (blue), and $\mathrm{O}$ (pink) in $\mathrm{NiB}_{i} / \mathrm{GDY}$. The above results show that the $\mathrm{NiB}_{i} / \mathrm{GDY}$ hybrid was successfully

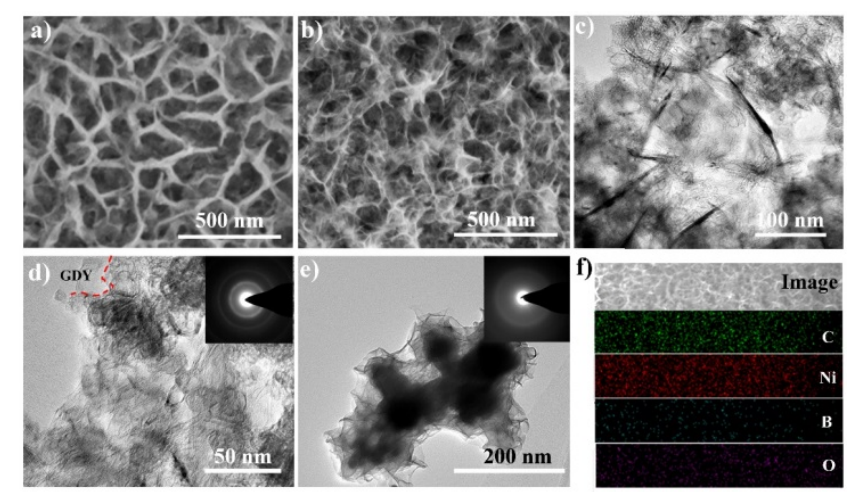

Fig. 1. SEM images of GDY (a) and $\mathrm{NiB}_{i} / \mathrm{GDY}(\mathrm{b})$; TEM images of $\mathrm{Ni}$ $\mathrm{B}_{i} / \mathrm{GDY}(\mathrm{c}, \mathrm{d})$ and $\mathrm{NiB}_{i}(\mathrm{e})$; The insets of $\mathrm{d}$ and e are the corresponding SAED images of $\mathrm{NiB}_{i} / \mathrm{GDY}$ and $\mathrm{NiB}_{i}$, respectively; (f) EDS mapping images of $\mathrm{NiB}_{i} / \mathrm{GDY}$. 
synthesized via in situ growth of $\mathrm{NiB}_{i}$ on GDY.

The chemical compositions and electronic structures of samples were evaluated by XRD, Raman spectroscopy, and XPS. As exhibited in Fig. 2a, the XRD pattern of $\mathrm{NiB}_{i} / \mathrm{GDY}$ demonstrates no distinct diffraction patterns attributable to crystalline nickel compounds, corresponding to the results of the SAED measurements. Fig. $2 \mathrm{~b}$ shows the Raman spectrum of GDY, which contains four distinct peaks at 1394.4, 1544.4, 1923.8, and $2183.3 \mathrm{~cm}^{-1}$ in accordance with reported data [25]. Specifically, the peaks at 1394.4 and $1544.4 \mathrm{~cm}^{-1}$ are attributed to the $\mathrm{D}$ band (the breathing vibration of $s p^{2}$ carbons) and $\mathrm{G}$ band (the first-order scattering of the $E_{2 \mathrm{~g}}$ mode of the in-phase stretching vibration of $s p^{2}$ carbons) of aromatic rings, respectively. Meanwhile, the peaks at 1923.8 and $2183.3 \mathrm{~cm}^{-1}$ belong to the typical vibrations of conjugated diyne links $(-\mathrm{C} \equiv \mathrm{C}-\mathrm{C} \equiv \mathrm{C}-)$ in GDY. As for $\mathrm{NiB}_{i} / \mathrm{GDY}$, the $\mathrm{G}$ band peak exhibited an obvious hypsochromic shift to $1580.7 \mathrm{~cm}^{-1}$ due to electronic interactions and the electron-donating nature of GDY [28]. In addition, the peaks assigned to $-\mathrm{C} \equiv \mathrm{C}-\mathrm{C} \equiv \mathrm{C}$ - became weaker compared to those of GDY, which could be attributed to the formation of chemical interactions between $\mathrm{NiB}_{i}$ and GDY [37]. As shown in Fig. S3, the survey XPS pattern shows the presence of $\mathrm{C}, \mathrm{O}, \mathrm{B}$, and $\mathrm{Ni}$ in $\mathrm{NiB}_{i} / \mathrm{GDY}$, which is consistent with the results of the EDS analysis. The high-resolution $\mathrm{C} 1 s$ spectrum of $\mathrm{NiB}_{i} / \mathrm{GDY}$ is shown in Fig. S4a. The $\mathrm{C} 1 \mathrm{~s}$ peak can be deconvoluted into four subpeaks at 284.42, 285.09, 286.40, and $288.57 \mathrm{eV}$, which can be assigned to $\mathrm{C}-\mathrm{C}\left(s p^{2}\right), \mathrm{C}-\mathrm{C}(s p), \mathrm{C}-\mathrm{O}$, and $\mathrm{C}=\mathrm{O}$ species, respectively [38]. The high-resolution $\mathrm{Ni} 2 p$ spectra of $\mathrm{NiB}_{i}$ and $\mathrm{NiB}_{i} / \mathrm{GDY}$ were also compared. As shown in
Figs. S4b and $\mathrm{S} 4 \mathrm{c}, \mathrm{NiB}_{i}$ showed two distinct Ni $2 p_{3 / 2}$ sub-peaks located at 855.9 and $875.5 \mathrm{eV}$, which could correspond to $\mathrm{Ni}^{2+}$ and $\mathrm{Ni}^{3+}$, respectively (as a result of the partial oxidization of the surface). On the other hand, $\mathrm{NiB}_{i} / \mathrm{GDY}$ exhibited one main $\mathrm{Ni} 2 p_{3 / 2}$ peak located at $855.74 \mathrm{eV}$, which is slightly lower than that seen in $\mathrm{NiB}_{i}$, indicating a lower valence of $\mathrm{Ni}$ than $\mathrm{Ni}^{2+}$. This lower valence state demonstrates the strong interaction between $\mathrm{NiB}_{i}$ and GDY, which could optimize the electronic structure and enhance the catalytic performance, as reported in the literature [39-41]. Furthermore, the binding energies of the peaks attributed to $\mathrm{Ni} 2 p_{3 / 2}$ and $\mathrm{Ni} 2 p_{1 / 2}$ in $\mathrm{NiB}_{i}$ and $\mathrm{Ni}-$ $\mathrm{B}_{i}$ /graphene are higher than those seen for $\mathrm{NiB}_{i}$ /GDY (Figs. $2 \mathrm{c}$ and $\mathrm{S5}$ ), indicating the presence of $\mathrm{Ni}$ ions with lower valence states in $\mathrm{NiB}_{i} /$ GDY than those seen in $\mathrm{NiB}_{i}$ and $\mathrm{NiB}_{i} /$ graphene. This demonstrates that the strong coupling effect between $\mathrm{NiB}_{i}$ and GDY in the $\mathrm{NiB}_{i} / \mathrm{GDY}$ hybrid has efficiently tuned the electronic structure of $\mathrm{NiB}_{i}$. In addition, the $\mathrm{B} 1 \mathrm{~s}$ spectrum of $\mathrm{Ni}$ $\mathrm{B}_{i} /$ GDY shows a peak at $192.1 \mathrm{eV}$ (Fig. 2d). This can be attributed to $\mathrm{B}^{3+}$ from boron oxide species, proving the successful formation of $\mathrm{NiB}_{i} / \mathrm{GDY}$.

The photocatalytic $\mathrm{H}_{2}$ evolution performances of $\mathrm{NiB}_{i} / \mathrm{GDY}$, $\mathrm{NiB}_{i} /$ graphene, $\mathrm{NiB}_{i}$, and GDY were measured in aqueous solutions using TEOA as a sacrificial reagent and EY as a photosensitizer under visible light irradiation $(\lambda>400 \mathrm{~nm})$. As shown in Fig. 3a, the time courses of the photocatalytic $\mathrm{H}_{2}$ evolution reactions demonstrate that $\mathrm{NiB}_{i} / \mathrm{GDY}$ showed the best $\mathrm{H}_{2}$ evolution activity. The amount of $\mathrm{H}_{2}$ evolved by $\mathrm{NiB}_{i} / \mathrm{GDY}$ increased sharply with the time, reaching $31.78 \mathrm{mmol} / \mathrm{g}$ after $7 \mathrm{~h}$. This was 2.9 and 4.5 times higher than the performances of $\mathrm{Ni}$ -
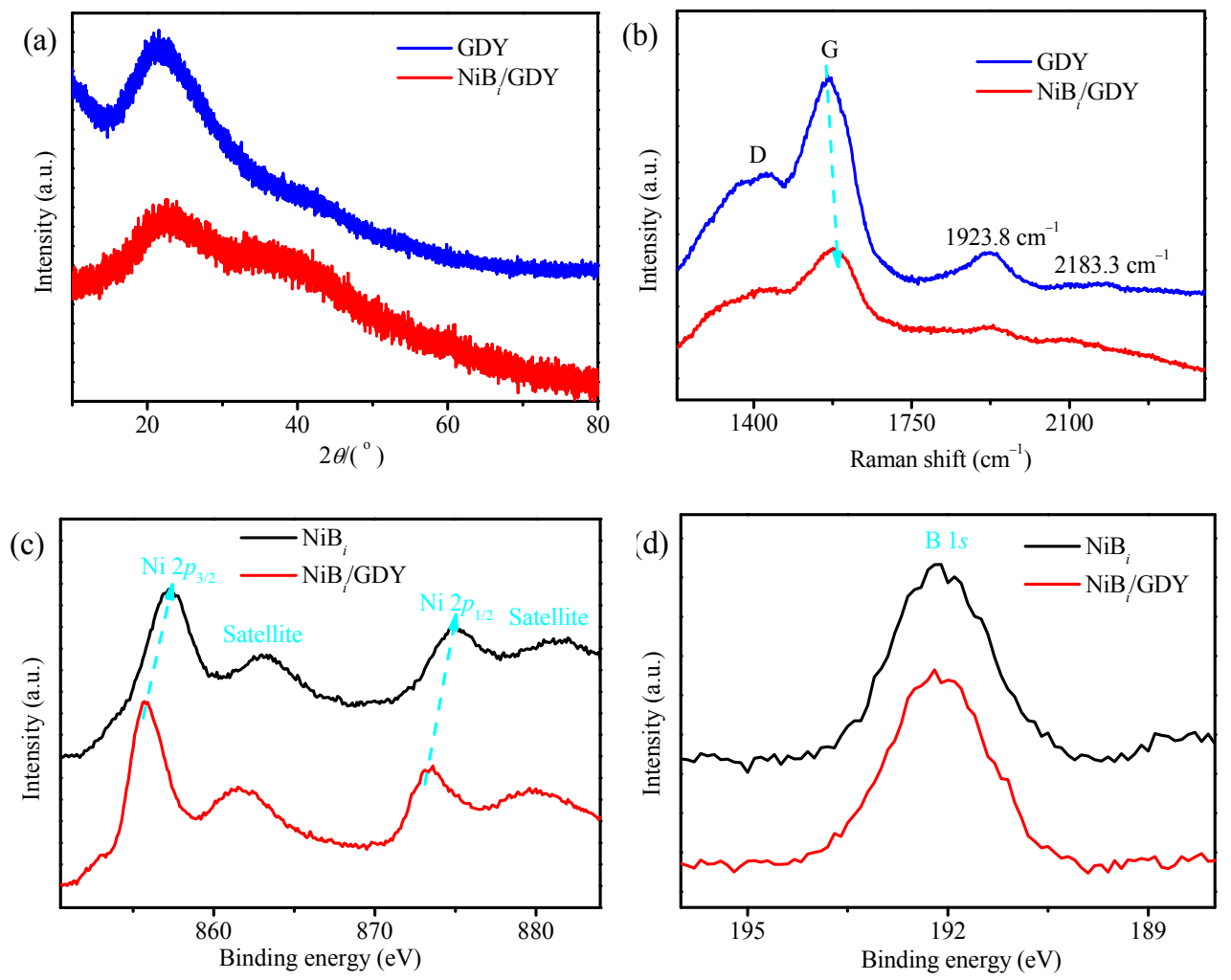

Fig. 2. (a) XRD patterns of GDY and $\mathrm{NiB}_{i} / \mathrm{GDY}$, (b) Raman spectra of GDY and $\mathrm{NiB}_{i} / \mathrm{GDY}$, (c) $\mathrm{Ni} 2 p$, and (d) B $1 s$ XPS patterns of $\mathrm{NiB}_{i}$ and $\mathrm{NiB}_{i} / \mathrm{GDY}$. 

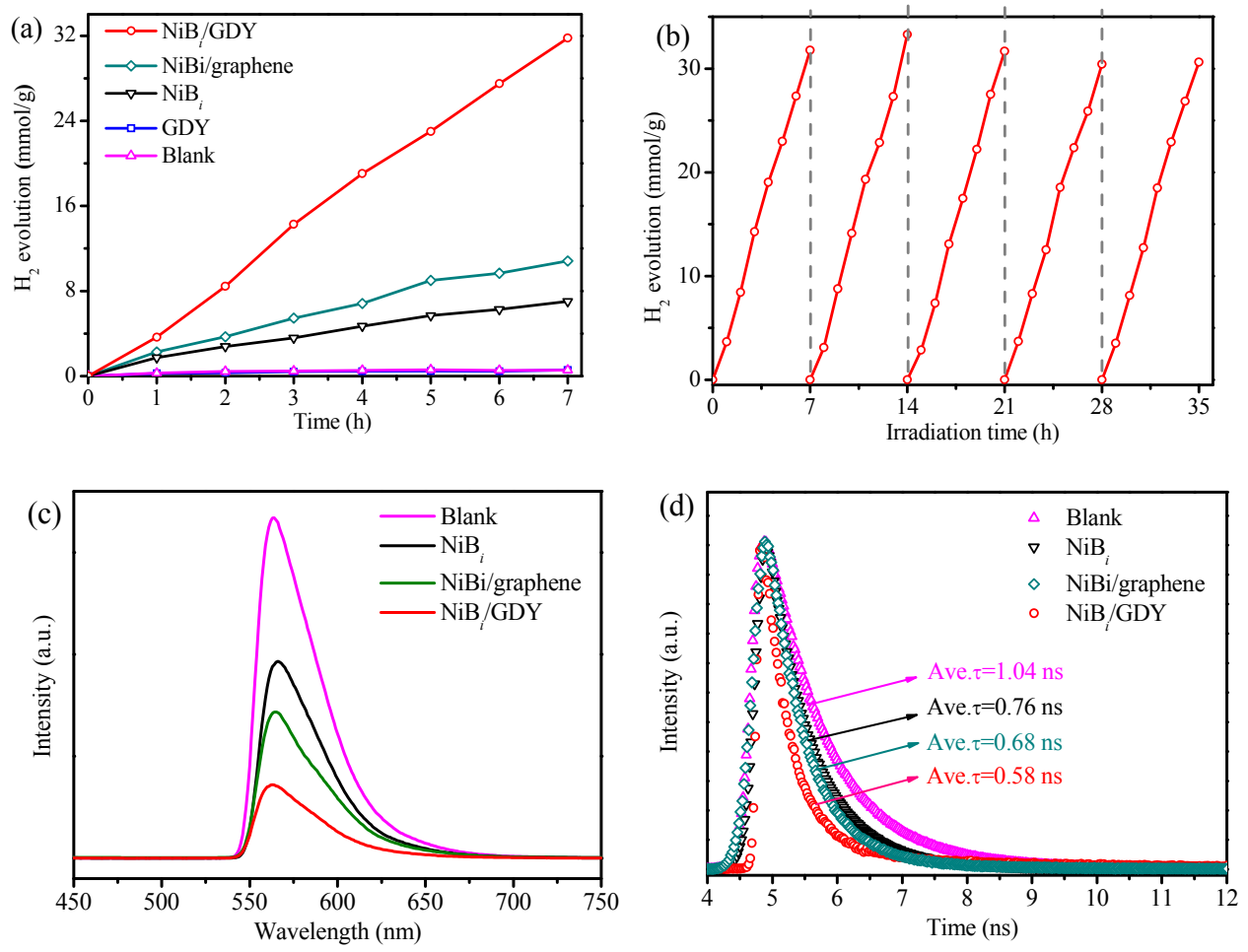

Fig. 3. (a) Time dependence of photocatalytic $\mathrm{H}_{2}$ generation using $\mathrm{NiB}_{i} / \mathrm{GDY} \mathrm{NiB}_{i} /$ graphene, $\mathrm{NiB}_{i}$, and GDY catalysts (Reaction conditions: 2 mg catalyst, $3 \mathrm{mg}$ Eosin Y, $5 \mathrm{~mL}$ aqueous solution containing $10 \mathrm{vol} \%$ TEOA, Xe-lamp $(300 \mathrm{~W}, \lambda>400 \mathrm{~nm})$ ). (b) Photocatalytic activity recycling test for Ni$\mathrm{B}_{i} / \mathrm{GDY}$. (c) Steady-state photoluminescence spectra of $\mathrm{NiB}_{i} / \mathrm{GDY}, \mathrm{NiB}_{i} /$ graphene, and $\mathrm{NiB}_{i}$. (d) Time-resolved fluorescence decay spectra of $\mathrm{NiB}_{i} / \mathrm{GDY}$, $\mathrm{NiB}_{i} /$ graphene, and $\mathrm{NiB}_{i}$.

$\mathrm{B}_{i}$ /graphene $(10.82 \mathrm{mmol} / \mathrm{g})$ and $\mathrm{NiB}_{i}(7.02 \mathrm{mmol} / \mathrm{g})$, respectively. The high $\mathrm{H}_{2}$ evolution activity of $\mathrm{NiB}_{i} / \mathrm{GDY}$ can be attributed to its two-dimensional $\pi$-conjugated structure, superior electrical conductivity, and the large specific surface area of GDY. The stability of $\mathrm{NiB}_{i} / \mathrm{GDY}$ when used for $\mathrm{H}_{2}$ evolution was also measured by re-dispersing the catalyst in fresh EY/TEOA reaction solutions every 7 h. As shown in Fig. S6a and Fig. 3 b, $\mathrm{NiB}_{i} / \mathrm{GDY}$ maintained its photocatalytic performance 11 $\mathrm{h}$, showing no loss in $\mathrm{H}_{2}$ yield after 5 cycles of $7 \mathrm{~h}$, displaying its excellent stability. Meanwhile, a TEM image of $\mathrm{NiB}_{i} / \mathrm{GDY}$ after the photocatalytic reaction was also taken (Fig. S6b), confirming the stability of the hybrid during the photocatalytic reaction. In contrast, when using the same ratio of $\mathrm{NiB}_{i}$ to GDY in $\mathrm{NiB}_{i} / \mathrm{GDY}$, the mixture showed poor $\mathrm{H}_{2}$ reduction activity (Fig. S7). This comparison highlights the importance of the strong coupling effect between GDY and $\mathrm{NiB}_{i}$ in $\mathrm{NiB}_{i} /$ GDY, which optimizes the electronic structure of $\mathrm{NiB}_{i}$ and enhances the photocatalytic HER performance.

The apparent quantum efficiency (AQE) of $\mathrm{NiB}_{i} / \mathrm{GDY}$ is shown in Fig. S8. To better comprehend the photocatalytic process, the photoluminescence (PL) and time-resolved fluorescence (TRF) spectra measured. As shown in Fig. 3c, the PL spectrum of an aqueous solution of EY without any catalyst (blank) showed the strongest emission due to severe recombination of photoinduced charge carriers and low $\mathrm{H}_{2}$ evolution activity. Meanwhile, obvious PL quenching was observed when $\mathrm{NiB}_{i}, \mathrm{NiB}_{i} /$ graphene, or $\mathrm{NiB}_{i} / \mathrm{GDY}$ were added to the EY solution, demonstrating that the presence of these materials signif- icantly promoted the separation of photoinduced charge carriers and that they could act as photocatalysts for $\mathrm{H}_{2}$ evolution. To further understand the photophysical characteristics of the photoexcited carriers in these systems, the TRF spectra of the samples were measured. As shown in Fig. 3d, the average lifetimes obtained from the TRF spectra of blank, $\mathrm{NiB}_{i}, \mathrm{Ni}-$ $\mathrm{B}_{i}$ /graphene, and $\mathrm{NiB}_{i} / \mathrm{GDY}$ samples were $1.04,0.76,0.68$, and $0.58 \mathrm{~ns}$, respectively. These results demonstrate that $\mathrm{NiB}_{i} / \mathrm{GDY}$ displayed an obvious improvement in the charge carrier separation efficiency in EY solutions when compared to $\mathrm{Ni}$ $\mathrm{B}_{i}$ /graphene and $\mathrm{NiB}_{i}$, corresponding to the results of the PL measurements. In short, $\mathrm{NiB}_{i} /$ GDY possesses a good ability to promote the separation of photoinduced electrons and holes generated in EY due to the strong coupling effect, resulting in extremely high catalytic activity and stability when used for photocatalytic $\mathrm{H}_{2}$ evolution.

The electrocatalytic HER activities of $\mathrm{NiB}_{i} / \mathrm{GDY}, \mathrm{Ni}-$ $\mathrm{B}_{i}$ /graphene, $\mathrm{NiB}_{i}$, and GDY were also investigated in $1.0 \mathrm{M}$ $\mathrm{KOH}$ using a standard three-electrode electrochemical cell. Commercial Pt/C (20 wt\%) was used as a reference to accurately evaluate the HER activity. Linear sweep voltammetry (LSV) curves of the different samples were measured at a scan rate of $5 \mathrm{mV} / \mathrm{s}$, as shown in Fig. 4 a. As expected, $\mathrm{NiB}_{i} / \mathrm{GDY}$ showed enhanced HER activity when compared to GDY, Ni$\mathrm{B}_{i} /$ graphene, and $\mathrm{NiB}_{i}$. Notably, $\mathrm{NiB}_{i} / \mathrm{GDY}$ achieved a high current density of $400 \mathrm{~mA} / \mathrm{cm}^{2}$ at an overpotential of $478.0 \mathrm{mV}$, whereas a higher overpotential of $505.3 \mathrm{mV}$ was required to achieve such a current density for the commercial Pt/C catalyst. 

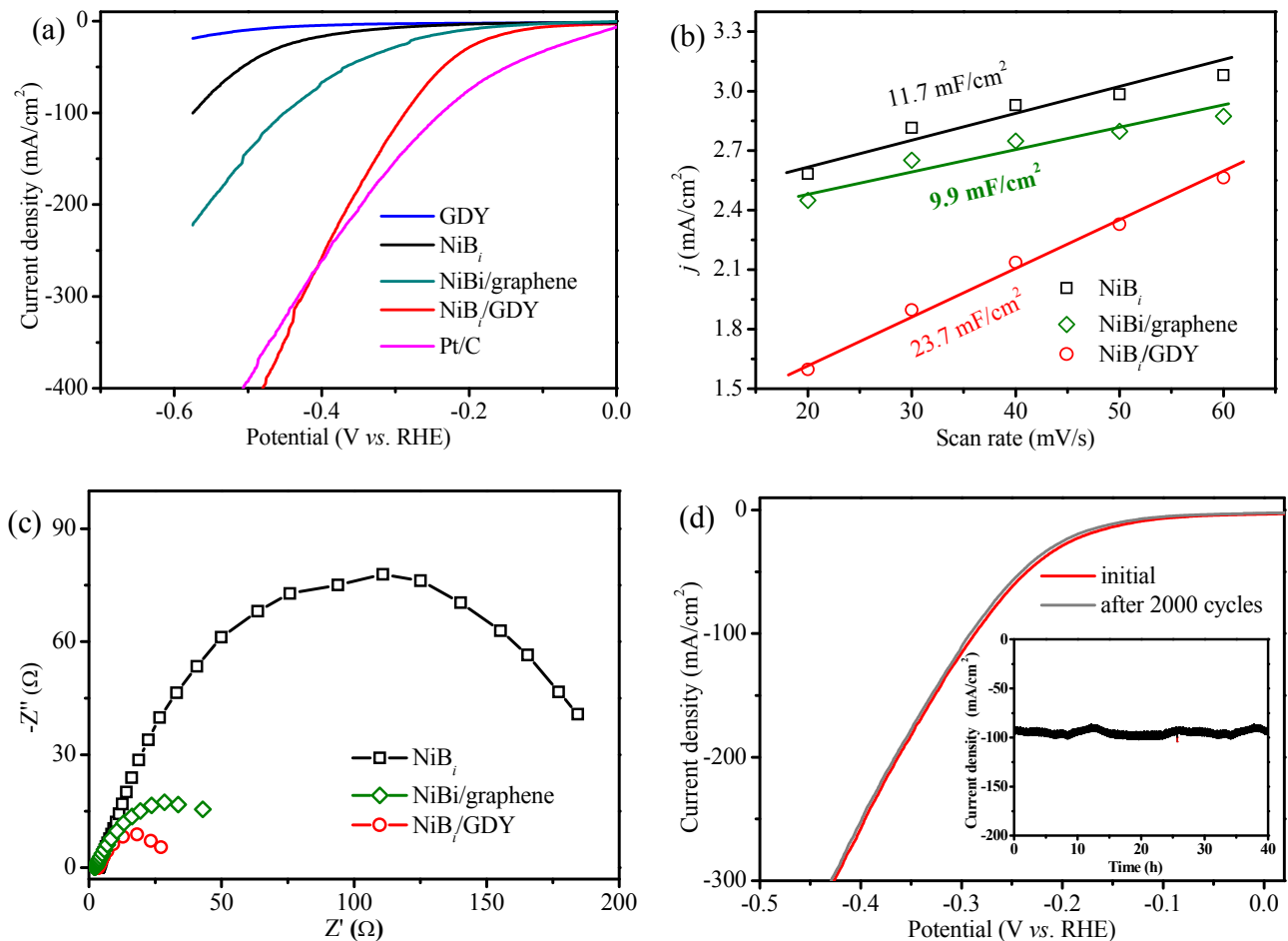

Fig. 4. (a) LSV curves of electrochemical HER activities. (b) Electrochemical surface area (ECSA) measurements of $\mathrm{NiB}_{i} / \mathrm{GDY} \mathrm{NiB}_{i} / \mathrm{graphene}$, and $\mathrm{NiB}_{i}$ vs. scan rate. (c) Nyquist plots for $\mathrm{NiB}_{i}, \mathrm{NiB}_{i} /$ graphene, and $\mathrm{NiB}_{i} / \mathrm{GDY}$ samples at $-0.2 \mathrm{~V}$ vs. RHE. (d) Polarization curves of $\mathrm{NiB}_{i} / \mathrm{GDY}_{\text {obtained initially }}$ and after 2000 cycles (inset: time dependence of the cathodic current density of $\mathrm{NiB}_{i} / \mathrm{GDY}$ over $40 \mathrm{~h}$ ).

In addition, Fig. $\mathrm{S} 9$ shows that the Tafel slope of $\mathrm{NiB}_{i} / \mathrm{GDY}$ was $156.1 \mathrm{mV} \mathrm{dec}^{-1}$, lower than that of $\mathrm{NiB}_{i}\left(298.0 \mathrm{mV} \mathrm{dec}^{-1}\right)$, demonstrating that the Volmer step was rate-determining and that rapid HER kinetics were realized in $\mathrm{NiB}_{i} / \mathrm{GDY}$ by accelerating the Volmer reaction [42]. The excellent HER performance of $\mathrm{NiB}_{i} / \mathrm{GDY}$ was possibly due to the strong coupling between $\mathrm{NiB}_{i}$ and GDY, the latter of which significantly improves the conductivity of $\mathrm{NiB}_{i} / \mathrm{GDY}$. The electrochemical surface areas of $\mathrm{NiB}_{i}, \mathrm{NiB}_{i}$ /graphene, and $\mathrm{NiB}_{i} / \mathrm{GDY}$ were evaluated using their double-layer capacitances $\left(C_{\mathrm{dl}}\right)$, which were obtained from $\mathrm{CV}$ curves measured in the non-Faradic potential range from $0.644-0.744 \mathrm{~V}$ at rates varying from $20-60 \mathrm{mV} / \mathrm{s}$ in $1.0 \mathrm{M} \mathrm{KOH}$ (Figs. $4 \mathrm{~b}$ and $\mathrm{S} 10$ ). The $C_{\mathrm{dl}}$ of $\mathrm{NiB}_{i} / \mathrm{GDY}$ was calculated to be $23.7 \mathrm{mF} / \mathrm{cm}^{2}$, much higher than those of $\mathrm{NiB}_{i}\left(11.7 \mathrm{mF} / \mathrm{cm}^{2}\right)$ and $\mathrm{NiB}_{i} /$ graphene $\left(9.9 \mathrm{mF} / \mathrm{cm}^{2}\right)$, indicating a higher number of exposed active sites after the formation of the $\mathrm{NiB}_{i} / \mathrm{GDY}$ hybrid. To further understand the kinetic of the HER, Nyquist plots were measured (Fig. 4c), with these showing that the charge transfer resistance of $\mathrm{NiB}_{i} / \mathrm{GDY}$ was much lower than those of $\mathrm{NiB}_{i}$ and $\mathrm{NiB}_{i}$ /graphene. Moreover, both current density-time and long-term CV cycling curves (2000 cycles) confirmed the stability of $\mathrm{NiB}_{i} /$ GDY during the HER (Fig. 4d).The $\mathrm{Ni}$ $2 p$ XPS profiles were also compared to determine the stability of $\mathrm{NiB}_{i} / \mathrm{GDY}$ during the HER. As shown in Fig. S11, the oxidation states of the catalysts after the electrocatalytic $\mathrm{H}_{2}$ evolution test were similar to those of the as-prepared samples, showing the good stability of $\mathrm{NiB}_{i} / \mathrm{GDY}$. These results illustrate that $\mathrm{Ni}$ $\mathrm{B}_{i} / \mathrm{GDY}$ possessed excellent activity and stability for the electrocatalytic HER.

\section{Conclusions}

In summary, we have successfully prepared a new $\mathrm{NiB}_{i} / \mathrm{GDY}$ hybrid at room temperature via a facile chemical strategy, and investigated its HER catalytic performance for photo/electrocatalytic water splitting. Benefitting from the strong coupling effect between GDY and $\mathrm{NiB}_{i}$, the electron-donating GDY lowered the valence of nickel in $\mathrm{NiB}_{i} / \mathrm{GDY}$, resulting in an optimized electronic structure and enhanced photocatalytic HER performance for the $\mathrm{NiB}_{i} / \mathrm{GDY}$ hybrid. This material showed a $\mathrm{H}_{2}$ evolution rate of $4.54 \mathrm{mmol} \mathrm{g}^{-1} \mathrm{~h}^{-1}$, which was 2.9 and 4.5 times higher than those of $\mathrm{NiB}_{i} /$ graphene and $\mathrm{NiB}_{i}$, respectively, and demonstrated a better electrocatalytic HER performance than commercial $\mathrm{Pt} / \mathrm{C}$ at high current density. This work not only provides a facile method for the construction of a highly efficient GDY-based catalyst for the HER, but also brings new insights into the development of non-noble-metal catalysts.

\section{Electronic supporting information}

Supporting information is available in the online version of this article.

\section{Conflict of Interest}

The authors declare no conflict of interest. 


\section{Graphical Abstract}

Chin. J. Catal., 2021, 42: 1379-1386 doi: 10.1016/S1872-2067(20)63601-4

\section{In situ synthesis of a nickel boron oxide/graphdiyne hybrid for} enhanced photo/electrocatalytic $\mathrm{H}_{2}$ evolution

Xue-Peng Yin, Shu-Wen Luo, Shang-Feng Tang, Xiu-Li Lu*, Tong-Bu Lu* Tianjin University of Technology

A new nickel boron oxide/graphdiyne ( $\left.\mathrm{NiB}_{i} / \mathrm{GDY}\right)$ hybrid is synthesized by a facile room-temperature synthesis approach and shows outstanding photocatalytic and electrocatalytic $\mathrm{H}_{2}$ evolution activities.

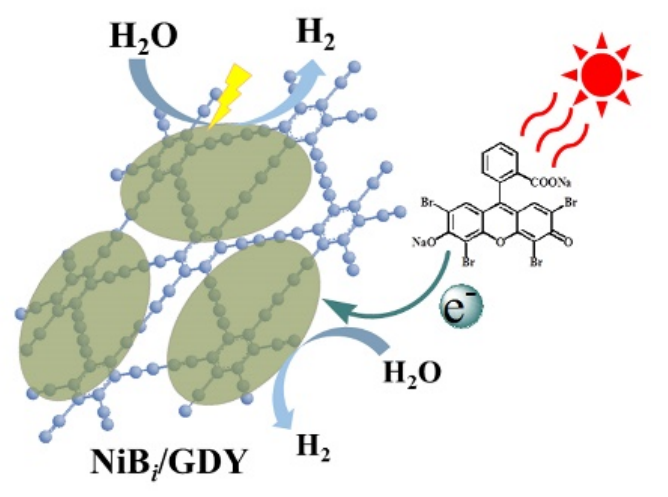

\section{References}

[1] K. Chen, S. Q. Ci, Q. H. Xu, P. W. Cai, M. Z. Li, L. J. Xiang, X. Hu, Z. H. Wen, Chin. J. Catal., 2020, 41, 858-867.

[2] J. Ran, W. Guo, H. Wang, B. Zhu, J. Yu, S. Z. Qiao, Adv. Mater., 2018, 30, 1800128.

[3] D. D. Li, Y. M. Dong, G. L. Wang, P. P. Jiang, F. Y. Zhang, H. Z. Zhang, J. Li, J. Z. Lyu, Y. Wang, Q. Y. Liu, Chin. J. Catal., 2020, 41, 889-897.

[4] Q. Liu, J. Tian, W. Cui, P. Jiang, N. Cheng, A. M. Asiri, X. Sun, Angew. Chem. Int. Ed., 2014, 53, 6710-6714.

[5] Q. Xu, B. Zhu, B. Cheng, J. Yu, M. Zhou, W. Ho, Appl. Catal. B, 2019, 255,117770

[6] M. Z. Rahman, K. Davey, S. Z. Qiao, J. Mater. Chem. A, 2018, 6, 1305-1322.

[7] L. Liang, Y. Sun, F. Lei, S. Gao, Y. Xie, J. Mater. Chem. A, 2014, 2, 10647-10653.

[8] Y. Xu, B. Zhang, Chem. Soc. Rev., 2014, 43, 2439-2450.

[9] C. Guo, X. Liu, L. Gao, X. Ma, M. Zhao, J. Zhou, X. Kuang, W. Deng, X. Sun, Q. Wei, J. Mater. Chem. A, 2019, 7, 21704-21710.

[10] Z. Zhang, W. Li, M. F. Yuen, T. W. Ng, Y. Tang, C. S. Lee, X. Chen, W. Zhang, Nano Energy, 2015, 18, 196-204.

[11] D. Voiry, H. Yamaguchi, J. W. Li, R. Silva, D. C. B. Alves, T. Fujita, M. W. Chen, T. Asefa, V. B. Shenoy, G. Eda, M. Chhowalla, Nat. Mater., 2013, 12, 850-855.

[12] J. Xie, L. Gao, H. Jiang, X. Zhang, F. Lei, P. Hao, B. Tang, Y. Xie, Cryst. Growth Des., 2019, 19, 60-65.

[13] C. Huang, Y. Huang, C. Liu, Y. Yu, B. Zhang, Angew. Chem. Int. Ed., 2019, 58, 12014-12017.

[14] H. Jin, X. Liu, S. Chen, A. Vasileff, L. Li, Y. Jiao, L. Song, Y. Zheng, S. Z. Qiao, ACS Energy Lett., 2019, 4, 805-810.

[15] B. You, Y. Zhang, Y. Jiao, K. Davey, S. Z. Qiao, Angew. Chem. Int. Ed., 2019, 58, 11796-11800.

[16] K. Xu, H. Ding, M. Zhang, M. Chen, Z. Hao, L. Zhang, C. Wu, Y. Xie, Adv. Mater., 2017, 29, 1606980.

[17] H. Lin, Z. Shi, S. He, X. Yu, S. Wang, Q. Gao, Y. Tang, Chem. Sci., 2016, 7, 3399-3405.

[18] P. Chen, K. Xu, T. Zhou, Y. Tong, J. Wu, H. Cheng, X. Lu, H. Ding, C. Wu, Y. Xie, Angew. Chem. Int. Ed., 2016, 55, 2488-2492.
[19] M. Q. Yang, J. D. Dan, S. J. Pennycook, X. Lu, H. Zhu, Q. H. Xu, H. J. Fan, G. W. Ho, Mater. Horiz., 2017, 4, 885-894.

[20] Z. C. Zhuang, Y. Li, Z. L. Li, F. Lv, Z. Q. Lang, K. N. Zhao, L. Zhou, L. Moskaleva, S. J. Guo, L. Q. Mai, Angew. Chem. Int. Ed., 2018, 57, 496-500.

[21] J. Bao, J. F. Xie, F. C. Lei, Z. L. Wang, W. J. Liu, L. Xu, M. L. Guan, Y. Zhao, H. M. Li, Catalysts, 2018, 8, 350.

[22] J. Bao, X. Zhang, L. Bai, W. Bai, M. Zhou, J. Xie, M. Guan, J. Zhou, Y. Xie, J. Mater. Chem. A, 2014, 2, 10876-10881.

[23] F. Li, R. Xu, Y. Li, F. Liang, D. Zhang, W. F. Fu, X. J. Lv, Carbon, 2019, 145, 521-528.

[24] L. Najafi, S. Bellani, R. OropesaNuñez, M. Prato, B. Martín García, R. Brescia, F. Bonaccorso, ACS nano, 2019, 13, 3162-3176.

[25] G. Li, Y. Li, H. Liu, Y. Guo, Y. Li, D. Zhu, Chem. Commun., 2010, 46, 3256-3258.

[26] J. Li, Z. Xie, Y. Xiong, Z. Li, Q. Huang, S. Zhang, J. Zhou, R. Liu, X. Gao, C. Chen, L. Tong, J. Zhang, Z. Liu, Adv. Mater., 2017, 29, 1700421.

[27] J. X. Lv, Z. M. Zhang, J. Wang, X. L. Lu, W. Zhang, T. B. Lu, ACS Appl. Mater. Interfaces, 2019, 11, 2655-2661.

[28] Y. Y. Han, X. L. Lu, S. F. Tang, X. P. Yin, Z. W. Wei, T. B. Lu, Adv. Energy Mater., 2018, 8, 1702992.

[29] H. Yu, Y. Xue, L. Hui, C. Zhang, Y. Zhao, Z. Li, Y. Li, Adv. Funct. Mater., 2018, 28, 1707564.

[30] Y. Yao, Z. Jin, Y. Chen, Z. Gao, J. Yan, H. Liu, J. Wang, Y. Li, S. Liu, Carbon, 2018, 129, 228-235.

[31] Y. Xue, J. Li, Z. Xue, Y. Li, H. Liu, D. Li, W. Yang, Y. Li, ACS Appl. Mater. Interfaces, 2016, 8, 31083-31091.

[32] L. Hui, D. Jia, H. Yu, Y. Xue, Y. Li, ACS Appl. Mater. Interfaces, 2019, $11,2618-2625$.

[33] X. Yin, D. Lu, J. Wang, X. Lu, ChemCatChem, 2019, 11, 5407-5411.

[34] Y. Fang, Y. Xue, L. Hui, H. Yu, Y. Liu, C. Xing, F. Lu, F. He, H. Liu, Y. Li, Nano Energy, 2019, 59, 591-597.

[35] J. Zhou, X. Gao, R. Liu, Z. Xie, J. Yang, S. Zhang, G. Zhang, H. Liu, Y. Li, J. Zhang, Z. Liu, J. Am. Chem. Soc., 2015, 137, 7596-7599.

[36] Q. Zhu, B. Qiu, M. Du, M. Xing, J. Zhang, Ind. Eng. Chem. Res., 2018, 57, 8125-8130.

[37] H. Ren, H. Shao, L. Zhang, D. Guo, Q. Jin, R. Yu, L. Wang, Y. Li, Y. Wang, H. Zhao, D. Wang, Adv. Energy Mater., 2015, 5, 1500296.

[38] X. Gao, J. Li, R. Du, J. Zhou, M. Y. Huang, R. Liu, J. Li, Z. Xie, L. Z. Wu, 
Z. Liu, J. Zhang, Adv. Mater., 2017, 29, 1605308.

[39] C. Zhu, A. L. Wang, W. Xiao, D. Chao, X. Zhang, N. H. Tiep, S. Chen, J. Kang, X. Wang, J. Ding, J. Wang, H. Zhang, H. J. Fan, Adv. Mater., 2018, 30, 1705516.

[40] T. Liu, A. Li, C. Wang, W. Zhou, S. Liu, L. Guo, Nanoscale, 2018, 30,
1803590.

[41] M. Q. Yang, J. Dan, S. J. Pennycook, X. Lu, H. Zhu, Q. H. Xu, H. J. Fan, G. W. Ho, Mater. Horiz., 2017, 4, 885-894.

[42] L. Diao, B. Zhang, Q. Sun, N. Wang, N. Zhao, C. Shi, E. Liu, C. He, Nanoscale, 2019, 11, 21479-21486.

\title{
原位合成氧化镍硼/石墨炔杂化材料用于提高光/电催化产氢性能
}

\author{
殷学鹏 ${ }^{\dagger}$, 罗舒文 ${ }^{\dagger}$, 唐上峰, 卢秀利 ${ }^{*}$, 鲁统部
}

天津理工大学材料科学与工程学院新能源材料与低碳技术研究院, 材料微结构教育部国际合作联合实验室, 天津 300384

\begin{abstract}
摘要: 当今世界面临严峻的能源紧缺和环境污染问题, 发展高效无污染的清洁能源替代传统化石能源成为近几十年科研 工作者的研究热点. 其中, 氢能由于具有高燃烧值和产物无污染等优点成为理想的替代能源. 光/电催化水分解产生氢气 是最有效的制氢方法之一. 目前, 高活性的产氢催化剂仍以贵金属为主, 但贵金属价格高昂和稀缺性等限制了其大规模应 用, 因此, 开发和设计廉价、高效的非贵金属产氢催化剂变得尤为重要. 为了提高非贵金属催化剂的催化活性, 基于非贵金 属的复合材料的构建被广泛研究. 例如, 通过非贵金属和碳材料的复合, 能够提高比表面积和电子传输速率, 优化活性位 点的电子结构, 从而提高催化活性.

石墨炔(GDY)作为一种新兴碳材料, 由 $s p^{2}$-和 $s p$-杂化碳共同组成. 由于GDY具有高度 $\pi$ 共轭结构, 大的比表面积和独特 的双炔键, 可作为载体与非贵金属离子相互作用形成复合材料, 制备高效产氢催化剂. 基于此, 本文在室温下原位合成了 强耦合相互作用的氧化镍硼/石墨炔 $\left(\mathrm{NiB}_{i} / \mathrm{GDY}\right)$ 催化剂, 并将其应用于光/电催化产氢反应. 在光催化产氢反应中, 采用曙 红为光敏剂, 三乙醇胺为牺牲剂, 可见光下 $\mathrm{NiB}_{i} / \mathrm{GDY}$ 的光催化产氢速率可达 $4.54 \mathrm{mmol} \mathrm{g}^{-1} \mathrm{~h}^{-1}$, 产氢速率分别是氧化镍嗍/石 墨烯 $\left(\mathrm{NiB}_{i} /\right.$ graphene) 和 $\mathrm{NiB}_{i}$ 的2.9倍和4.5倍. 此外, $\mathrm{NiB}_{i} / \mathrm{GDY}$ 在1.0 M KOH溶液中也表现出良好电催化产氢性能, 电流密度 为 $400 \mathrm{~mA} / \mathrm{cm}^{2}$ 时其过电位为 $478.0 \mathrm{mV}$, 低于商业铂碳(505.3 mV@ $400 \mathrm{~mA} / \mathrm{cm}^{2}$ ). NiB $/$ /GDY在光/电催化产氢实验中表现出 的较好催化性能可归因于 $\mathrm{NiB}_{i}$ 和 GDY之间强耦合相互作用对 $\mathrm{NiB}_{i}$ 电子结构的优化. 上述研究结果表明, 石墨炔可作为理想 载体制备高效的光/电催化剂, 同时本文为设计高效稳定的非贵金属产氢催化剂提供了一定的借鉴意义.
\end{abstract}

关键词: 石墨炔; 杂化材料; 光/电催化剂; 水分解反应; 氢析出

收稿日期: 2020-01-06. 接受日期: 2020-02-02. 上网时间: 2021-04-05.

*通讯联系人. 电话/传真: (022)60215704; 电子信箱: luxiuli@email.tjut.edu.cn

通讯联系人. 电子信箱: lutongbu@tjut.edu.cn

†共同第一作者.

基金来源：天津市教委科研计划项目(2018KJ129).

本文的电子版全文由Elsevier出版社在ScienceDirect上出版(http://www.sciencedirect.com/journal/chinese-journal-of-catalysis). 